\title{
Back-analysis Crossrail deep excavation using 3D FE modelling -Development of BRICK parameters for London Clay
}

\author{
Y.Chen ${ }^{1}$, A.K.Pillai ${ }^{2}$, D.P.Nicholson ${ }^{2}$, G.Biscontin ${ }^{1}$ \\ 1. University of Cambridge, U.K.; 2. Ove Arup \& Partners, U.K.
}

\begin{abstract}
New underground stations up to $40 \mathrm{~m}$ deep for the Crossrail project in the London have been constructed. Excavations were supported by diaphragm walls or secant pile wall, using either the top-down or bottom-up construction sequence. To investigate the effects of these deep excavations on the existing adjacent buildings and tunnels, 3D FE models have been developed. The non-linear elastic plastic soil constitutive model - BRICK was used to model the behavior of London Clay and Lambeth Group. A back-analysis of the field inclinometer data from Tottenham Court Road Station - Western Ticket Hall was carried out using the 3D FEM. Revised BRICK parameters were derived from the back-analysis and applied in three other Crossrail excavations. The back analysis of four excavations has provided an intensive review on the BRICK model parameters for London Clay. The reliability of the BRICK model in London Clay to assess most probable ground movements has been demonstrated.
\end{abstract}

\section{INTRODUCTION}

The demand for space in cities has been expanding with the urban population growth. This also affects underground development, particularly where new tunnels continue to be constructed close to existing tunnels and buildings' foundations. This increased underground congestion leads to additional difficulties for the construction of new underground structures in urban areas. In addition, increasing asset protection requirements for existing tunnels and piles have made excavation work even more complex. In order to address these issues for future excavation design, an accurate three-dimension finite element model (3D FEM) would be valuable for designers. The implementation of 3D FEM in design for excavations in London has been previously reported: Crossrail Liverpool Street Station - Moorgate Shaft (Zdravkovic, Potts and John, 2005; Farooq et al., 2015); King's Place development (Yeow and Feltham, 2008; Ellison, 2012); and One New Change basement (Fuentes, et al., 2010).

The soil constitutive model BRICK for London Clay was originally published by Simpson (1992) and the parameters were later reviewed by Pillai (1996). A more recent reassessment of BRICK parameters for London Clay was reported by Pillai and Fuentes (Pillai et al., 2011). These are referred to as moderately conservative parameters.

The Crossrail project included the construction of eight new underground stations in the central London area. This paper presents four excavation case histories collected from these newly constructed stations. They are shown on the Crossrail route map in Figure 1.

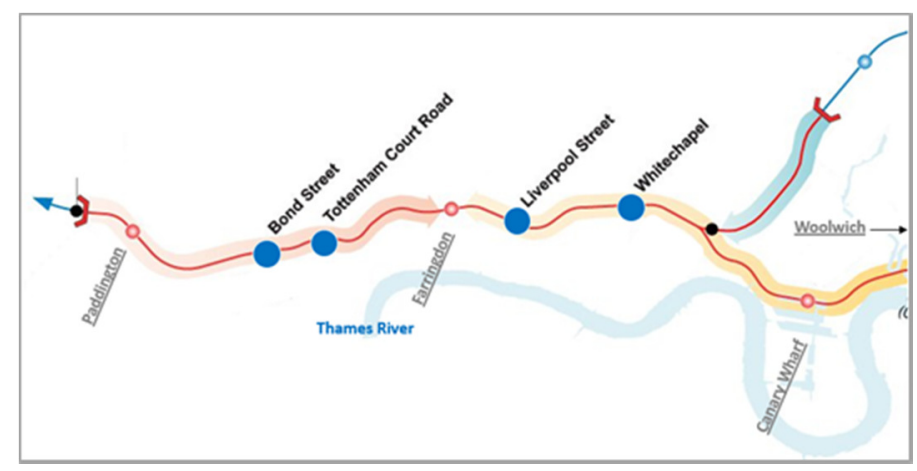

Figure 1 Crossrail route map at the central London area - locations of four excavation case histories (Crossrail, 2017)

During the original design stage in 2010, the ground movements and asset protection assessments for these new stations were conducted in 3D FEM (by LS-Dyna ${ }^{\circledR}$ ) using the BRICK soil model with the parameters updated by SCOUT (2007). This subsequent back-analysis of these Crossrail excavations has adopted the same analytical 3D FE models, but slightly modified for the as-built conditions. The aim is to back-analyse the case history performance of these excavations and develop most probable BRICK parameters for London Clay. These parameters give a most probable estimate of wall deflections for use in the observational method. (Hardy et al., 2017)

\section{BRICK PARAMETERS}

\subsection{Classic parameters}

The initial set of BRICK parameters for London Clay was proposed by Simpson (1992). The BRICK parameters have been updated for London Clay through projects in London Clay by Pillai (1996), 
and SCOUT (2007). These updated sets of parameters were considered as 'Characteristic' and 'Most Probable' by Pillai et al.(2011) and shown in Table 1. The definition of the latest BRICK parameters is given in Ellison et al.(2012).

Table 1 Latest updated BRICK parameters

\begin{tabular}{|c|c|c|}
\hline \multicolumn{2}{|c|}{ String length $\mathbf{L}_{(b)}$} & \multirow[b]{2}{*}{$\mathbf{G}_{\mathrm{t}} / \mathbf{G}_{\max }$} \\
\hline Characteristic $^{1}$ & Most Probable ${ }^{2}$ & \\
\hline 0.0000304 & 0.000030 & 0.92 \\
\hline 0.0000608 & 0.000075 & 0.75 \\
\hline 0.000101 & 0.00015 & 0.53 \\
\hline 0.000121 & 0.00040 & 0.29 \\
\hline 0.00082 & 0.00075 & 0.13 \\
\hline 0.00171 & 0.0015 & 0.075 \\
\hline 0.00352 & 0.0025 & 0.044 \\
\hline 0.00969 & 0.0075 & 0.017 \\
\hline 0.0222 & 0.02 & 0.0035 \\
\hline 0.0646 & 0.06 & 0 \\
\hline
\end{tabular}

Note: 1 . Characteristic BRICK parameters by Pillai (1996), $\lambda^{*}$ $=0.1, \kappa^{*}=0.02,1=0.0019, v=0.2, \mathrm{M}_{\mathrm{u}}=1.3, \beta^{\mathrm{G}}=\beta^{\varnothing}=4.0 .2$. Most Probable BRICK parameters by SCOUT (2007), $\lambda^{*}=$ $0.1, \kappa^{*}=0.02, \imath=0.00175, v=0.2, \mathrm{M}_{\mathrm{u}}=1.3, \beta^{\mathrm{G}}=\beta^{\varnothing}=4.0$.

The 'Most Probable' BRICK parameters were implemented in the initial Crossrail 3D FEM asset protection assessments in 2010. The predicted ground movements associated with the new tunnel boring machine (TBM) work and the deep excavations have been used for the existing structural damage assessments. They met the asset protection criteria specified by Crossrail or the relevant third parties.

\subsection{Calibration using Crossrail laboratory test data}

In preparation for this back-analysis, a calibration study has been undertaken using the laboratory triaxial testing data from boreholes along the 20-mile long Crossrail alignment in the central London.

London Clay is commonly divided into five units (A to E) (King, 1981), and the triaxial test results have been assessed using these London Clay units. Variations in the test results also depend on the quality of the samples and the test procedures. The BRICK parameters for London Clay Units A3 \& A2 have been calibrated and presented in Table 2 .

Details of calibration laboratory testing data will be given in Chen (2018). Lower small strain stiffness values have been observed for London Clay Unit $\mathrm{C} / \mathrm{B}$ from the triaxial laboratory testing. However, the limited number of the sample tested and the large range of values made calibration difficult. Therefore, the laboratory test calibrated BRICK parameters for the London Clay Unit A3 have been applied to the Unit C/B. Similarly, there are very few quality test results for Lambeth Group, so the laboratory test calibrated BRICK parameters for the London Clay Unit A2 have been adopted for the Lambeth Group.
Table 2 Calibrated BRICK parameters from triaxial tests

\begin{tabular}{lll}
\hline String length $\mathbf{L}_{(\mathbf{b})}$ & & \\
LC- A3 & LC- A2 & $\mathbf{G}_{\mathbf{t}} / \mathbf{G}_{\mathbf{m a x}}$ \\
\hline 0.0000304 & 0.000030 & 0.92 \\
0.0000608 & 0.000075 & 0.75 \\
0.000101 & 0.00015 & 0.53 \\
0.000121 & 0.00040 & 0.29 \\
0.00082 & 0.00075 & 0.13 \\
0.00171 & 0.0015 & 0.075 \\
0.00352 & 0.0025 & 0.044 \\
0.00969 & 0.0075 & 0.017 \\
0.0222 & 0.02 & 0.0035 \\
0.0646 & 0.06 & 0 \\
\hline
\end{tabular}

Note: for LC-A3: $\lambda^{*}=0.1, \kappa^{*}=0.02, \mathrm{l}=0.0019, v=0.2, \mathrm{M}_{\mathrm{u}}=$ 1.3, $\beta^{\mathrm{G}}=4.0$, and $\beta^{\varnothing}=2.0$. For LC-A2: $\lambda^{*}=0.1, \kappa^{*}=0.01, \mathrm{l}=$ $0.0015, v=0.2, \mathrm{M}_{\mathrm{u}}=1.3, \beta^{\mathrm{G}}=\beta^{\varnothing}=5.0$. (Chen, 2018)

\section{REVISED BRICK PARAMETERS}

\subsection{Calibration using inclinometer data - through TCR-WTH FEM back-analysis}

These "calibrated" BRICK parameters based on triaxial testing have been used to calculate wall deflections at the Tottenham Court Road Station - Western Ticket Hall (TCR-WTH) deep shaft excavation. However, differences of up to a factor of two remain between the measured and the calculated deflections.

After a careful review of the inclinometer data and the as-built construction details including excavation levels, wall, prop and waling stiffness, a number of back-analysis iterations have concluded that a stiffer set of BRICK parameters was needed to replicate the inclinometer data. Another set of revised London Clay BRICK parameters was developed based on the inclinometer data for TCR- WTH back-analysis and presented in Table 3 . These are referred to as "revised" BRICK parameters.

Table 3 Revised BRICK parameters based on inclinometer data

\begin{tabular}{ll}
\hline String length $\mathbf{L}_{(\mathbf{b})}$ & $\mathbf{G}_{\mathbf{t}} / \mathbf{G}_{\max }$ \\
LC-A3 \& LC-A2 & \\
\hline 0.000030 & 0.92 \\
0.000075 & 0.75 \\
0.00015 & 0.60 \\
0.00025 & 0.50 \\
0.0005 & 0.35 \\
0.0010 & 0.25 \\
0.0015 & 0.15 \\
0.0020 & 0.05 \\
0.0033 & 0.01 \\
0.06 & 0 \\
\hline
\end{tabular}

Note: $\lambda^{*}=0.1, \kappa^{*}=0.01,1=0.0015, v=0.2, \mathrm{M}_{\mathrm{u}}=1.3, \beta^{\mathrm{G}}=\beta^{\varnothing}$ = 5.0. (Chen, 2018)

\subsection{TCR-WTH deep box excavation}

The TCR-WTH deep shaft is almost in a rectangular shape, measuring about $41 \mathrm{~m} \times 31 \mathrm{~m}$ in plan. The maximum excavation depth is approximate to 29.5 
$\mathrm{m}$. The original design adopted a $1.0 \mathrm{~m}$ thick diaphragm wall with temporary props for a bottom-up construction sequence. The site layout and section are shown in Figure 2.

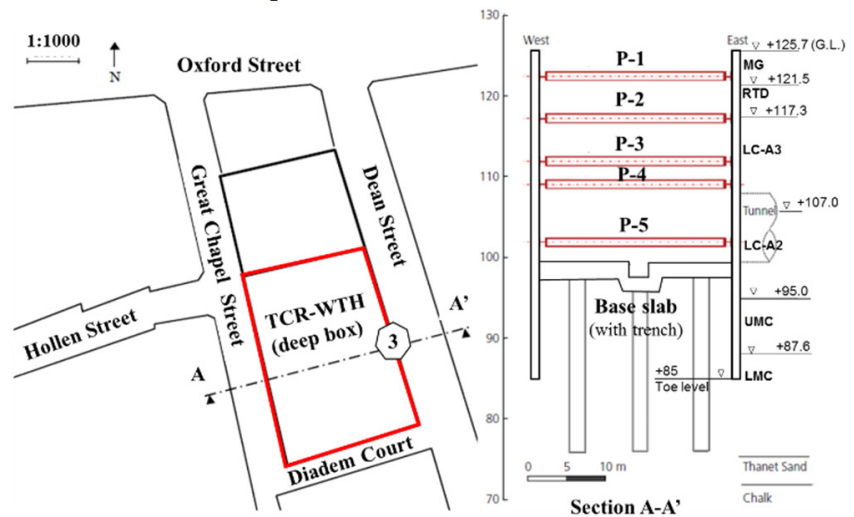

Figure 2 TCR-WTH layout plan and section (Bologna, 2017, Yeow, 2014)

To minimize the excavation duration, the observational method was adopted to modify the design during construction, allowing the lowest level of temporary props to be omitted. This reduced costs and saved about four weeks on the programme. (Yeow, 2014) The as-built construction sequence is summarised in Table 4.

Table 4 Summary of as-built construction sequence TCR-WTH

\begin{tabular}{lll}
\hline Stage & Description & $\begin{array}{l}\text { Formation level } \\
\text { (m ATD) }\end{array}$ \\
\hline 1 & Excavate 1 & +121.6 \\
2 & Install P-1 \& excavate 2 & +116.4 \\
3 & Install P-2 \& excavate 3 & +111.1 \\
4 & Install P-3 \& excavate 4 & +108.1 \\
5 & Install P-4 \& excavate 5 & +101.0 \\
6 & Excavate 6 \& cast base slab & +96.8 \\
\hline
\end{tabular}

After (Yeow, 2014; Chen et al., 2015)

The 3D FEM model for the TCR-WTH was updated with the as-built construction sequence and the most probable structural properties for the temporary props and the waler beams. All soil elements and the piles were modelled using solid elements. The retaining walls, capping beams, slabs, walers and other walls were modelled as shell elements. The temporary props were modelled using beam elements. The updated 3D FEM for TCR-WTH back-analysis is shown in Figure 3.

A ShapeArrayAccel (SAA) was installed in the TCR-WTH diaphragm wall panels to measure the wall deflection. SAA-3 measured the maximum wall deflection profile during the excavation and was adopted for the back-analysis. The location of SAA3 is indicated in the layout plan in Figure 2.

A comparison of the wall deflection profiles at stage 2, stage 4 and stage 6 in Table 4 is presented in Figure 4. At each stage, the calculated deflection profile by the calibrated BRICK parameters (shown as the broken lines in Figure 4) and the calculated deflection profile by the revised BRICK parameters

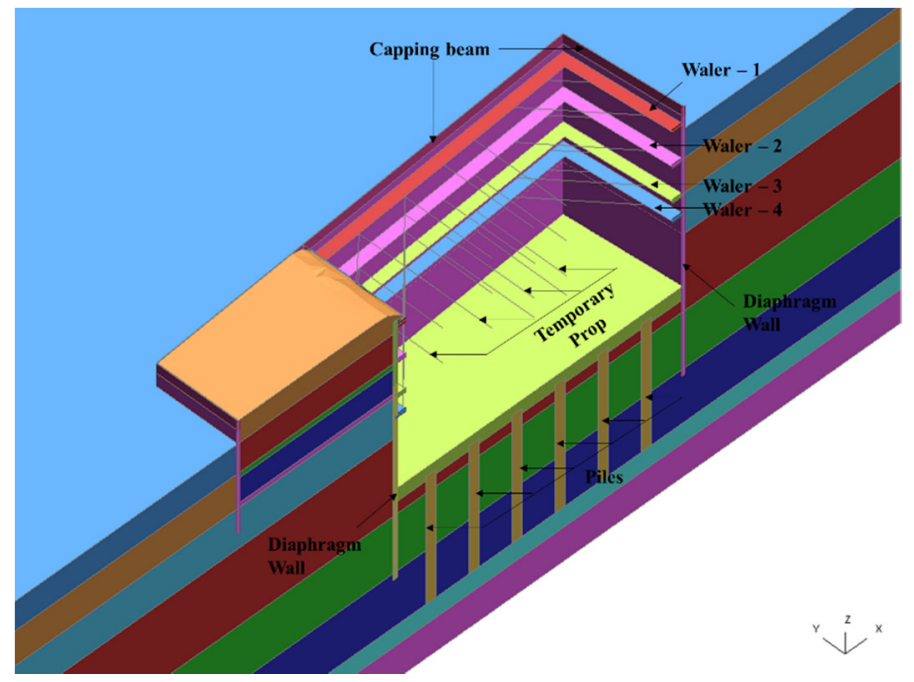

Figure 3 TCR-WTH 3D FEM - section along axis Y

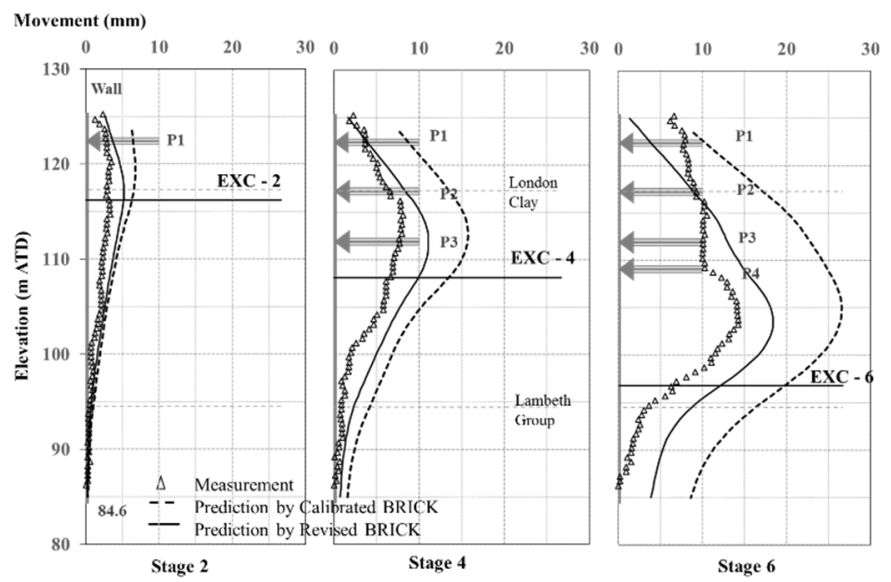

Figure 4 TCR-WTH SAA-3 wall deflection profiles: measurements compared with calculations

(shown as the solid lines in Figure 4) were compared with the inclinometer data. The predictions by the revised BRICK parameters have shown a significantly improved agreement with the inclinometer data.

In the TCR-WTH 3D FEM back-analysis, the Lambeth Group has been modelled by the revised BRICK parameters using a slightly higher over consolidation ratio (OCR) in order to stiffen the soil and control the wall deflection within the Lambeth Group. Details of this OCR adjustment will be given in Chen (2018).

In order to validate the TCR-WTH revised BRICK parameters for wall deflection calculation, three additional Crossrail deep excavations have been back-analysed using the revised BRICK parameters.

\section{CASE HISTORIES}

\subsection{Bond Street Station - Western Ticket Hall}

The Bond Street Western Ticket Hall (BS-WTH) is not far from the TCR-WTH site. This box measures $28 \mathrm{~m} \times 56 \mathrm{~m}$ in plan and the maximum excavation depth is about $26 \mathrm{~m}$ from existing ground level. The BS-WTH box is surrounded on four sides by local 


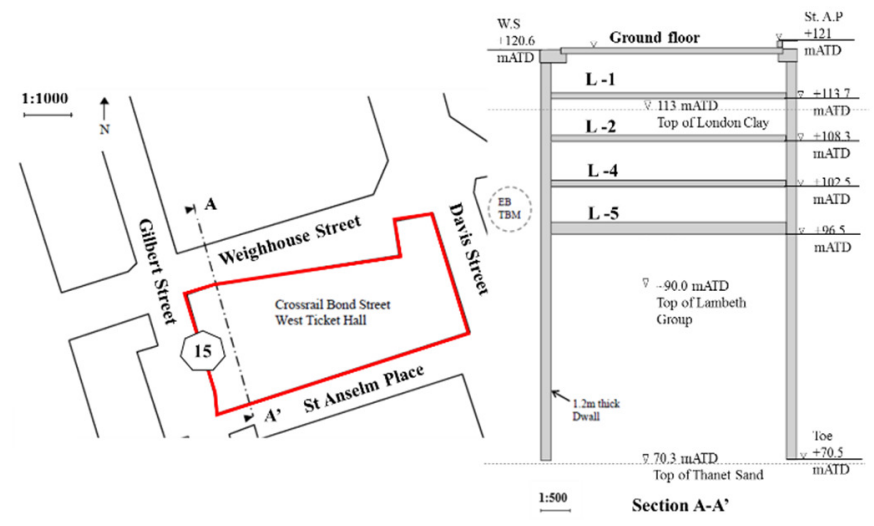

Figure 5 BS-WTH layout plan and section (Bologna, 2017)

roads with buildings beyond the roads. The layout of the site and the section are shown in Figure 5.

The box is supported by a $1.2 \mathrm{~m}$ thick diaphragm wall and constructed using a top-down excavation sequence. Permanent reinforced concrete slabs were installed during excavation and provided the required lateral support to the retaining wall. The TBM went past during the box excavation. Some compensation grouting work was also conducted as the box excavation progressed. The as-built construction sequence is summarised in Table 5.

Table 5 Summary of as-built construction sequence - BS-WTH

\begin{tabular}{lll}
\hline Stage & Description & $\begin{array}{l}\text { Formation level } \\
\text { (m ATD) }\end{array}$ \\
\hline 1 & Excavate 1 \& cast GF slab & +118.5 \\
2 & Excavate 2 \& cast L-1 slab & +112.2 \\
3 & Excavate 3 \& cast L-2 slab & +106.8 \\
$4^{*}$ & Westbound TBM transit & As above $(+106.8)$ \\
$5^{*}$ & Eastbound TBM transit & As above $(+106.8)$ \\
6 & Excavate 4 \& cast L-4 slab & +101.0 \\
7 & Excavate 5 \& cast L-5 slab & +95.0 \\
\hline
\end{tabular}

Note: stage $4 \& 5$ excluded in the 3D FEM reanalysis

(Bologna, 2017)

The 3D FEM of the BS-WTH was originally undertaken for the asset protection studies. The analysis included the existing tunnels and buildings, together with the new Crossrail TBM tunnels and SCL tunnels, see Figure 6. The back-analysis of BS-WTH has adopted the same 3D FE model with the revised BRICK parameters based on the TCR-WTH inclinometer data.

The ground movement case study by Bologna (2017) provides details of the construction of the Crossrail TBM tunnels. These run parallel to the BSWTH box diaphragm walls in the longitudinal direction, see Figure 6 . The tunnelling effects have been included in the inclinometer measurements but not modelled in the 3D FEM.

It is assumed that the tunneling effect has less impact on the walls along the axis perpendicular to the tunnel. Hence the inclinometer IN-15 installed in the middle of one short side next to Gilbert Street as indicated in the site layout plan in Figure 5, was selected for the back-analysis comparison. The calculated wall deflection profiles were compared with

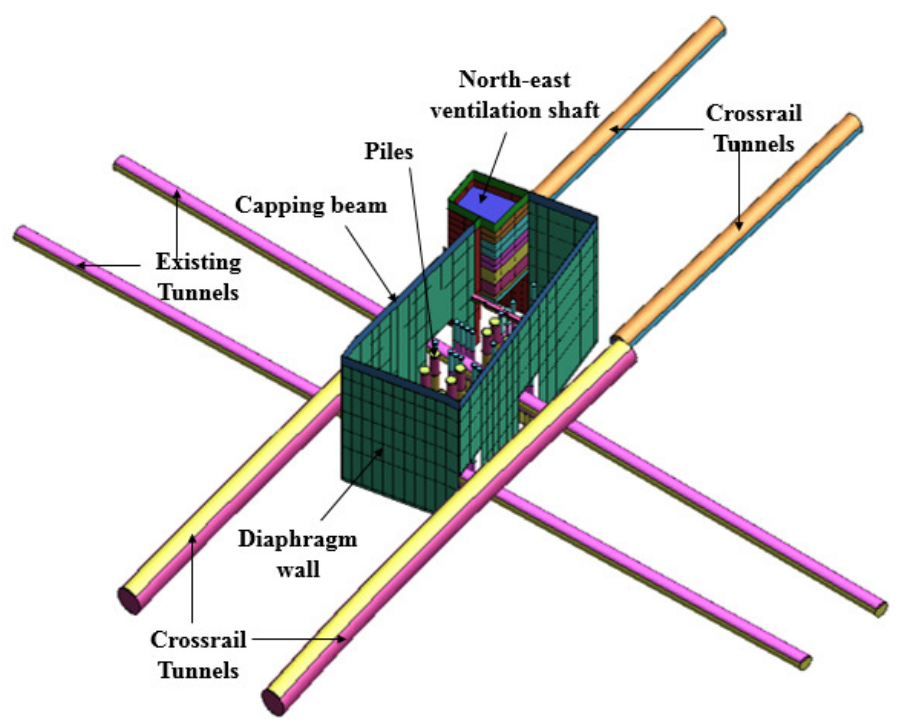

Figure 6 BS-WTH 3D FEM model

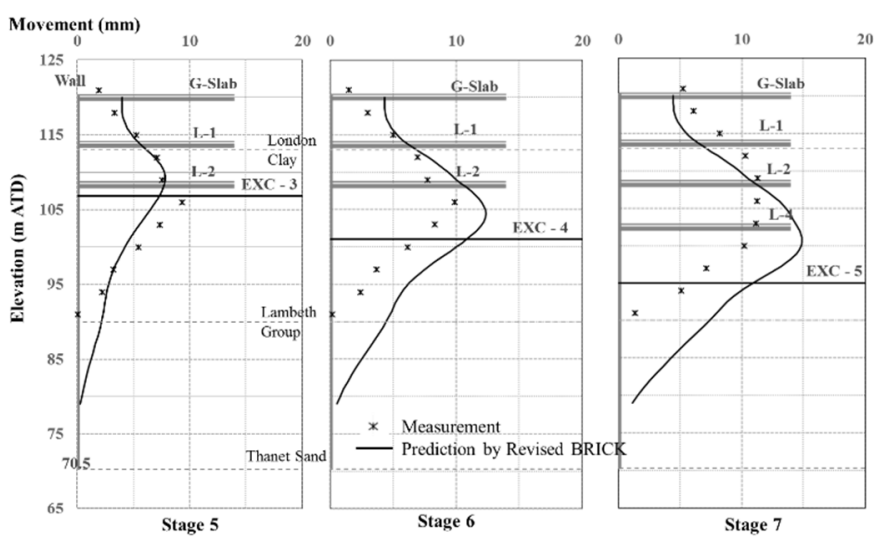

Figure 7 BS-WTH IN-15 wall deflection profiles: measurements compared with calculations using revised BRICK parameters

the measured deflection profiles from inclinometer IN-15 in Figure 7. In addition, the inclinometer data was only available from the beginning of the TBM tunnelling works (stage 4 in Table 5). Therefore, the wall deflection comparison was carried out for stage 5 to stage 7. Measured and calculated wall deflection profiles are compared in Figure 7 showing reasonable agreement.

\subsection{Liverpool Street Station-Moorgate Shaft}

The Moorgate Shaft is part of Liverpool Street Station (LIS-MS) structure. It is an octagonal shape, about $35 \mathrm{~m} \times 35 \mathrm{~m}$ in plan with the maximum excavation depth of about $39 \mathrm{~m}$ from existing ground level. The site layout plan and the section are presented in Figure 8.

The shaft is formed by a $1.2 \mathrm{~m}$ thick diaphragm wall in a depth of about $52 \mathrm{~m}$. Permanent propping to the shaft is provided by a series of ring beams forming the top-down excavation sequence. In the East-West direction, two cross-walls act as propping walls for the lower level during excavation. The initial design included two-levels of temporary props below the lowest ring beams (RBs) that would be removed after the installation of the base slab. 


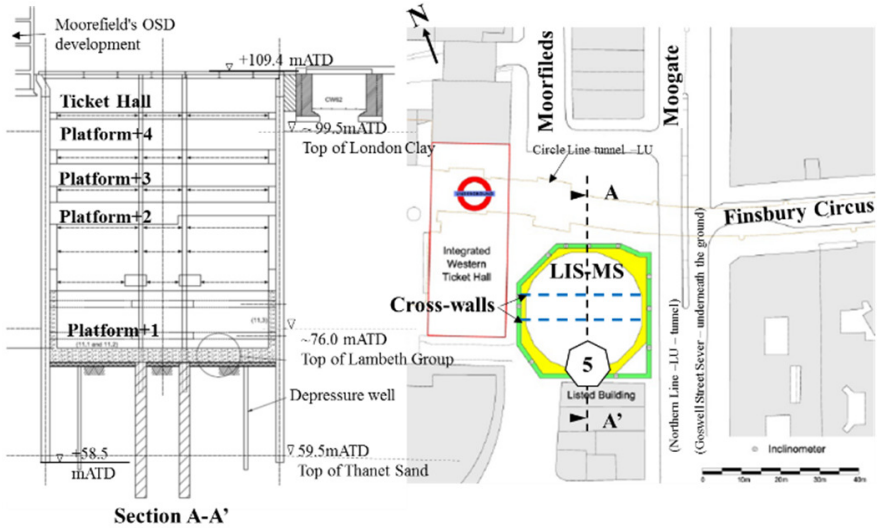

Figure 8 LIS-MS layout plan and section, after (Farooq et al., 2015)

Due to the delayed site obstruction clearance work, it became necessary to speed up the shaft construction to enable the twin TBMs to pass through the MS on time. The observational method was adopted to modify the design. Several excavation stages were successfully combined. The lowest two-levels of temporary propping was omitted.

The as-built construction sequence is presented in Table 6. The 3D FE model for the LIS-MS was updated with the as-built conditions as shown in Figure 9.

Table 6 Summary of as-built construction sequence of LIS-MS

\begin{tabular}{lll}
\hline Stage & Description & $\begin{array}{l}\text { Formation level } \\
\text { (m ATD) }\end{array}$ \\
\hline 1 & Capping beam \& excavate -1 & +106.1 \\
2 & Cast RB-1 \& excavate -2 & +100.3 \\
3 & Cast RB-2 \& excavate -3 & +94.4 \\
4 & Cast RB-3/4 \& excavate -4 & +87.6 \\
5 & Cast RB5/6 \& excavate -5 & +83.5 \\
6 & Cast RB7 \& excavate -6 & +79.1 \\
7 & Excavate -7 & +71.3 \\
8 & Cast base slab & - \\
\hline
\end{tabular}

(Farooq et al., 2015; Chen et al., 2015)

As the diaphragm walls at East-West direction have been affected by clay inclusions at the end of the two cross-walls (Chen et al., 2015), the wall along the North-South direction was reviewed in the 3D FEM back-analysis. Measurements taken at inclinometer IN-5 on the south side of diaphragm wall are shown in Figure 10. These measured deflections were compared with the calculated wall deflection using the TCR-WTH revised BRICK parameters. Consideration was also given to an adjacent development which took place behind the south side diaphragm wall.

The comparisons at construction stage 2 , stage 5 and stage 7 as listed in Table 6 are presented in Figure 10. Good agreement can be seen. There is some variation in the top $20 \mathrm{~m}$ of the wall deflection profiles, which is believed mainly attributed to the adjacent development.

At stage 5 and stage 7, the maximum predicted wall deflection value is slightly less than the meas-

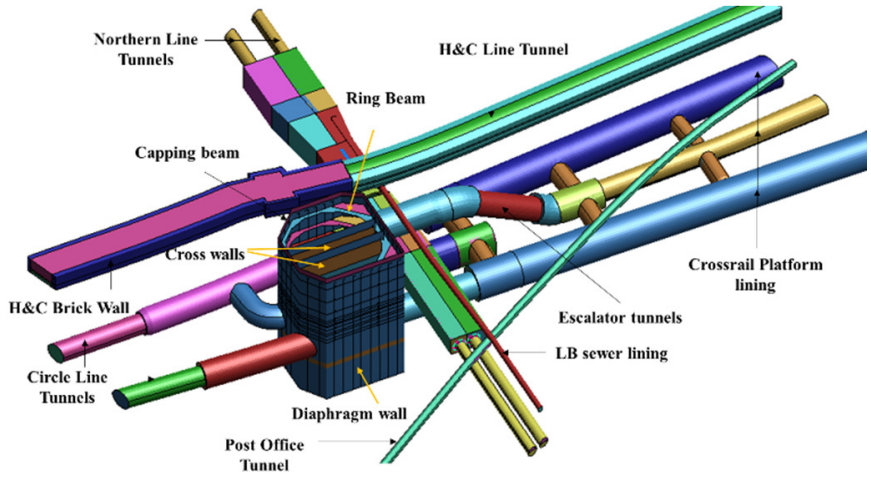

Figure 9 LIS-MS 3D FEM model

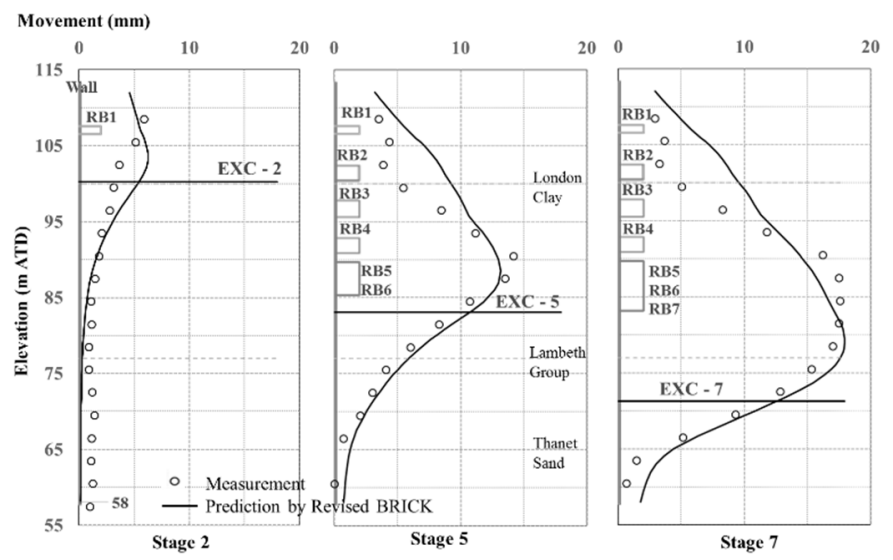

Figure 10 LIS-MS IN-5 wall deflection profiles: measurements compared with calculations using revised BRICK parameters

ured value (within $1.5 \mathrm{~mm}$ ). This could be associated with the selection of the Lambeth Group BRICK parameters. Noted that the final excavation stage occurred in the Lambeth Group clay.

\subsection{Whitechapel Station - Durward Street Shaft}

The Whitechapel Station, Durward Street Shaft (WS-DSS) was excavated in similar ground condition to the LIS-MS. The DS-DSS shaft is a hexagon shape, measuring about $59 \mathrm{~m} \times 32 \mathrm{~m}$ in plan with a maximum excavation depth of about $29.5 \mathrm{~m}$ from ground surface level. The perimeter diaphragm walls were $1.2 \mathrm{~m}$ thick and extended to a level of +70.1 mATD. The site layout plan and the section are shown in Figure 11.

A bottom-up sequence was adopted for the shaft construction as summarised in Table 7.

Table 7 Summary of as-built construction sequence of WS-DSS

\begin{tabular}{lll}
\hline Stage & Description & $\begin{array}{l}\text { Formation level } \\
\text { (m ATD) }\end{array}$ \\
\hline 1 & Excavate -1 & +109.0 \\
2 & Excavate -2 & +103.9 \\
3 & Excavate -3 & +102.9 \\
4 & Install prop L-4 at +104.3 & As above \\
5 & Excavate -4 & +94.4 \\
6 & Pre-stressed prop L-6 at +95.8 & As above \\
7 & Excavate -5 & +86.6 \\
8 & Pre-stressed prop L-7 at +87.5 & As above \\
9 & Excavate -6 & +81.7 \\
10 & Cast base slab & As above \\
\hline
\end{tabular}

(Mills, 2016) 


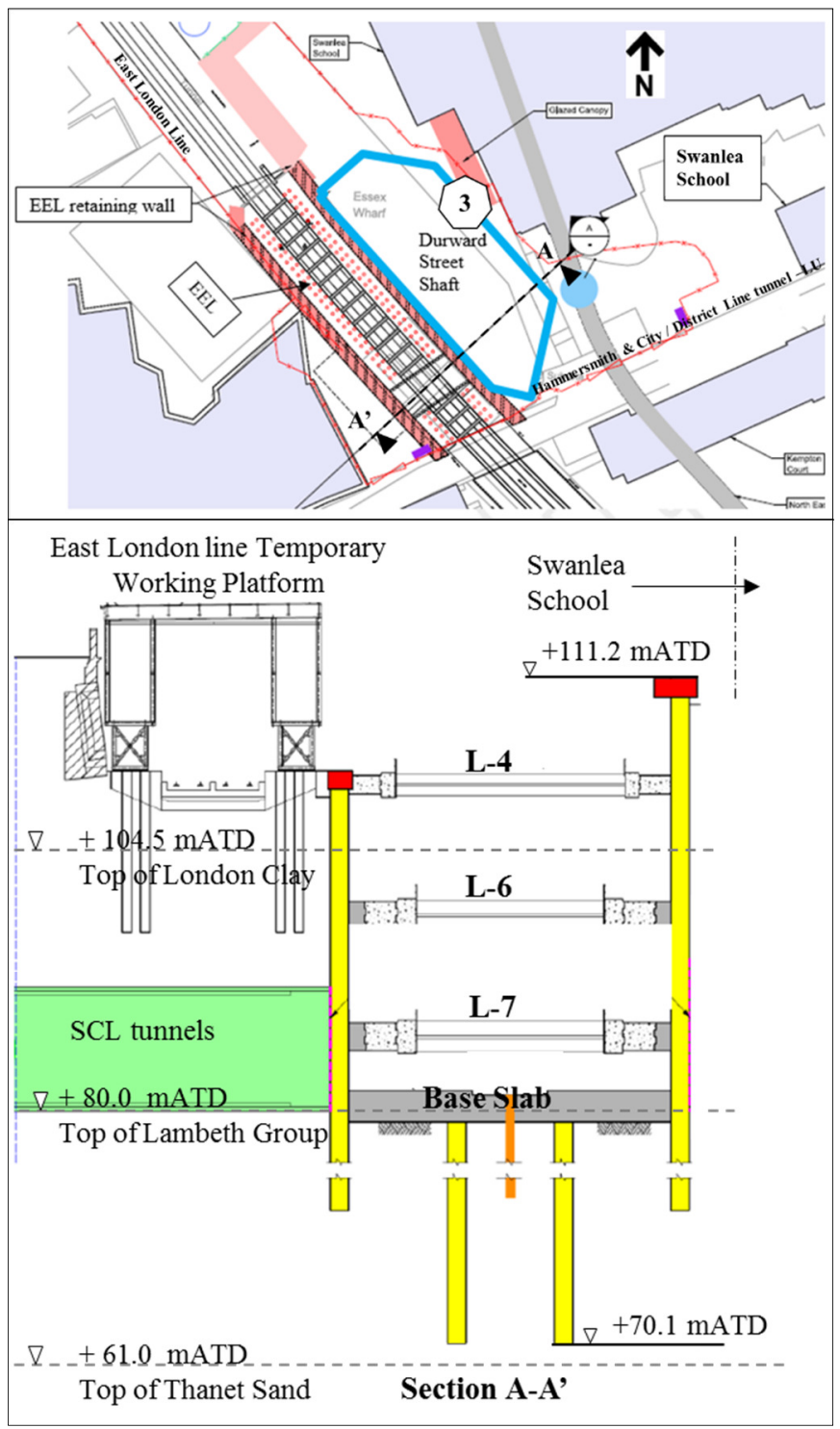

Figure 11 WS-DSS layout plan and section, after (Mills, 2016)

In order to speed up the excavation programme to cater for the TBM arrivals, the observational method was adopted from Stage 4 in Table 7 to modify the later excavation stages. The maximum wall deflection profiles at the WS-DSS measured from Inclinometer IN-3 was used to compare with the calculated wall deflection from the initial back-analysis. The back-analysis results showed that the early removal of the lowest level of props was acceptable without exceeding the design wall deflection criteria. (Mills, 2016)

In this subsequent back-analysis, the revised BRICK parameters from the TCR-WTH have been applied in the same 3D FE model for the WS-DSS as shown in Figure 12. The calculated wall deflection profiles are compared with the inclinometer IN3 data at stage 3 , stage 6 and stage 9 , as shown in Figure 13.

During the early cantilever excavation stages (stage 1 to stage 3 in Table 7), the maximum of up to 9.2 m excavation below ground level occurred, but the relativly large deflection at the deeper level was observed from IN-3 monitoring data. For example, about $5 \mathrm{~mm}$ movement was recorded at a depth of

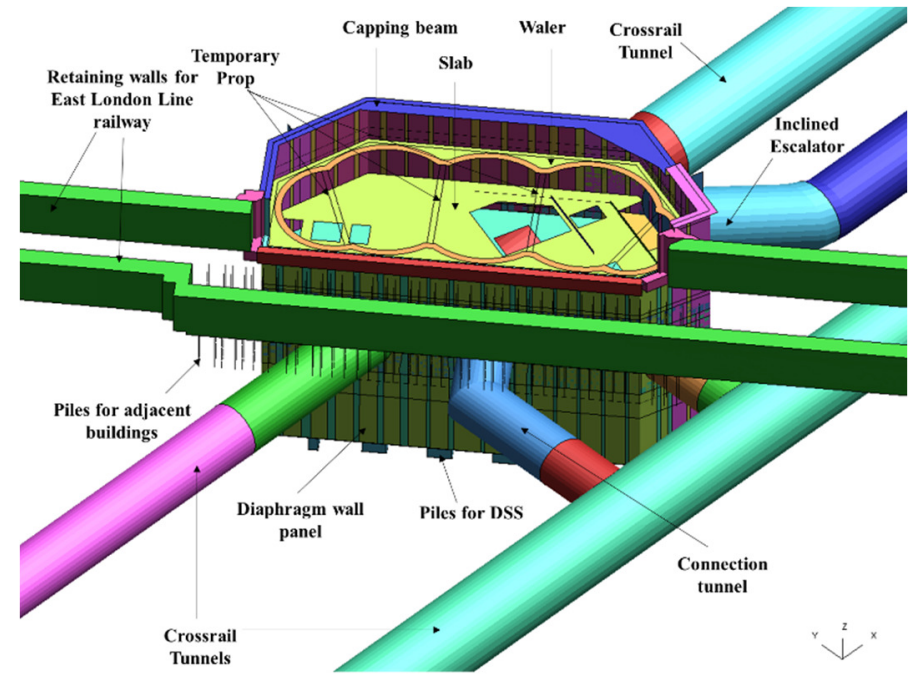

Figure 12 WS-DSS 3D FEM model

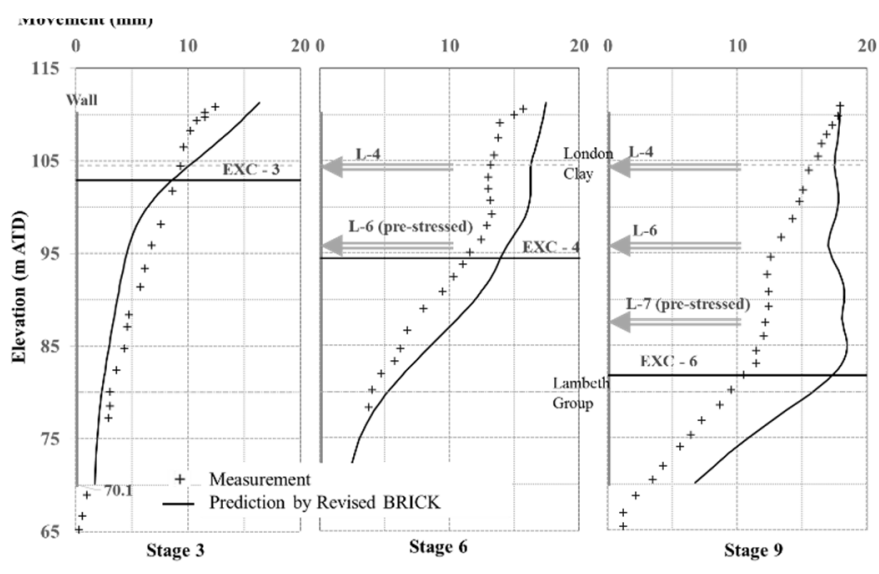

Figure 13 WS-DSS IN-3 wall deflection profiles: measurements compared with calculations using revised BRICK parameters

$10 \mathrm{~m}$ below the excavation level, and around $2.5 \mathrm{~mm}$ displacements in the Lambeth Group which is about $30 \mathrm{~m}$ below the excavation level. An inclinometer data review on IN-3 may explain these large displacements.

During the subsequent excavation stages when the excavation was propped, the calculated wall deflection profiles are similar to the measured profiles. A significant variance between measurements and predictions is observed in comparison at stage 9, in which the monitoring data has been restrained between the bottom in the Lambeth Group to the propping level L-6. This could be associated with the selection of the Lambeth Group BRICK parameters. Noted that the final excavation is immediately above the Lambeth Group clay.

\section{SUMMARY \& DISCUSSION}

\subsection{Summary of Crossrail excavation case histories}

Four Crossrail excavation case histories have been collected and back-analysed. The measured maximum wall deflections $\left(\delta_{\mathrm{H}, \mathrm{Max}}\right)$ are summarised in Table 8 together with the corresponding excavation 
depths $\left(\mathrm{H}_{\mathrm{e}}\right)$. This data is plotted onto historical data in Figure 14 and shows the Crossrail case histories have a ratio of $\delta_{H, M a x}$ to $\mathrm{H}_{\mathrm{e}}$ of about $0.05 \%$. This is smaller than previous experience.

Table 8 Summary of maximum wall deflection over excavation depth

\begin{tabular}{lcccc}
\hline Case & $\begin{array}{c}\delta_{\mathrm{H}, \mathrm{Max}} \\
(\mathrm{mm})\end{array}$ & $\begin{array}{c}\mathrm{H}_{\mathrm{e}} \\
(\mathrm{m})\end{array}$ & $\begin{array}{c}\delta_{\mathrm{H}, \mathrm{Max}} / \mathrm{H}_{\mathrm{e}} \\
(\%)\end{array}$ & Remark \\
\hline $\begin{array}{l}\text { TCR-WTH } \\
(\mathrm{SAA}-3)\end{array}$ & 14.24 & 29.5 & $0.05 \%$ & $\begin{array}{c}\mathrm{B} / \mathrm{L}=31 / 41 \\
(1.32)\end{array}$ \\
\hline $\begin{array}{l}{ }^{l} \mathrm{BS}-W T H \\
(I N-15)\end{array}$ & 11.29 & 26.0 & $0.04 \%$ & $\begin{array}{c}B / L=28 / 56 \\
(2.00)\end{array}$ \\
\hline $\begin{array}{l}\text { LIS-MS } \\
\text { (IN-5) }\end{array}$ & 17.58 & 38.8 & $0.05 \%$ & $\begin{array}{c}\mathrm{B} / \mathrm{L}=35 / 35 \\
(1.00)\end{array}$ \\
\hline $\begin{array}{l}{ }^{2} \text { WS-DSS } \\
\text { (IN-3) }\end{array}$ & 16.20 & 29.5 & $0.06 \%$ & $\begin{array}{c}\mathrm{B} / \mathrm{L}=32 / 59 \\
(1.84)\end{array}$ \\
\hline
\end{tabular}

Note: 1). BS-WTH measurement from IN-15 is on the short side of the excavation box, it may not represent the maximum wall deflection for this excavation case; 2). WS-DSS measurement from IN-3, the maximum movement is taken from below $+105 \mathrm{mATD}$ to mimic the cantilever excavation effect.

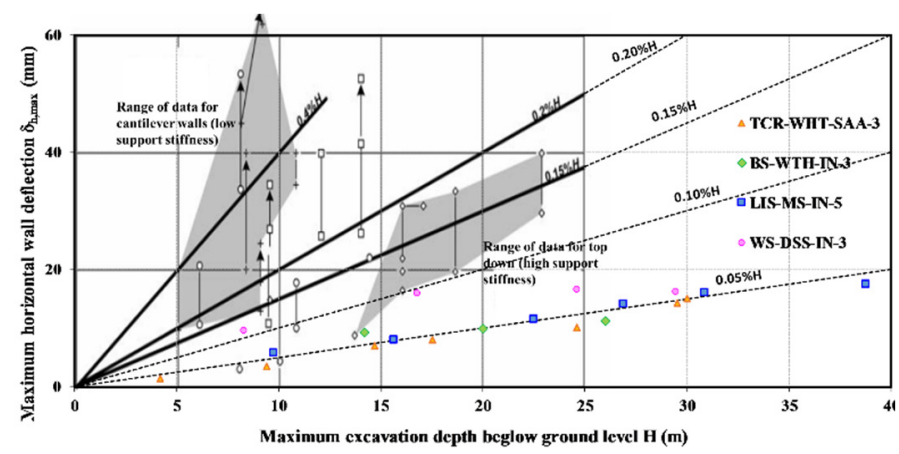

Figure 14 Observed maximum lateral wall deflections from excavations in London Clay, after Ciria C760 (Gaba et al., 2017)

\subsection{Discussion}

The soil stiffness was investigated using laboratory small strain triaxial testing data from the Crossrail ground investigations. Initially, the BRICK parameters for different London Clay Units were calibrated against these laboratory test. However, when the calibrated BRICK parameters were used in the 3D FEM, the calculated wall deflections were significantly larger than the inclinometer data. This implied that the laboratory tested small strain stiffness was not large enough.

The revised BRICK parameters were derived from the back-analysis of the TCR-WTH inclinometer data. Higher small strain stiffnesses were needed to match the inclinometer results compared with the triaxial laboratory test data. The in-situ self-boring pressure (SBP) testing data (Crossrail, 2009) was also reviewed and found to be stiffer than the triaxial test data. This indicates that the small strain triaxial laboratory testing did not accurately reflect the insitu soil behavior.
The Lambeth Group was initially modeled using the TCR-WTH revised BRICK parameters. This lead to the back-analysed wall deflections being slightly overestimated at the LIS-MS and the WHDSS case histories. In these two cases, the Lambeth Group was encountered at the bottom of the excavation. The further studies are needed to confirm the BRICK parameters for the Lambeth Group.

The Crossrail case histories show consistent ratio of $\delta_{\mathrm{H}, \mathrm{Max}}$ to $\mathrm{H}_{\mathrm{e}}$ of about $0.05 \%$. This is a smaller ratio compared with the historical data reported in Ciria C760 (St John et al., 1992; Gaba et al., 2017). It seems the stiff retaining wall and propping systems used on Crossrail achieved less-wall deflection in both the bottom-up and top-down methods compared with previous excavations in London Clay.

\section{CONCLUSIONS}

Back-analysis of four Crossrail deep excavation case histories have been carried out using the 3D FEM. The inclinometer wall deflection profiles have been used for the comparisons. Initially, the BRICK soil constitutive model parameters were calibrated using triaxial laboratory testing data. This led to overestimated wall deflections. Subsequently, revised BRICK parameters were developed, based on Crossrail TCR-WTH inclinometer data to fit the wall deflections.

All these back analyses have been carried out assuming undrained soil properties during the excavation work.

Particular care is required to interpretate the reliable inclinometer data.

The revised BRICK parameters for London Clay have been tested at three other Crossrail deep excavations, that had either bottom-up or top-down construction sequences. Good agreement has been achieved.

1) The revised BRICK parameters are considered to be 'most probable' or best estimate parameter values at this stage and can be used with the observational method in London Clay to predict wall deflections;

2) The assumption of using the revised London Clay BRICK parameters for the Lambeth Group is valid, although it may slightly overestimate the wall deflection when the excavation is close to or in the Lambeth Group;

3) The four Crossrail case histories recorded wall deflections which were consistently smaller than previous excavations in London Clay. Hence less impace on the surrouding structures. The reason for this needs further study. 


\section{NOTATION}

\begin{tabular}{|c|c|}
\hline $\mathrm{H}_{\mathrm{e}}$ & excavation depth \\
\hline$\delta_{\mathrm{H}, \mathrm{Max}}$ & maximum wall lateral displacement \\
\hline $\mathrm{G}_{\mathrm{t}}$ & shear modulus \\
\hline $\mathrm{G}_{\max }$ & the maximum shear modulus \\
\hline $\mathrm{G} / \mathrm{G}_{\max }$ & the proportion of material in BRICK \\
\hline$\lambda^{*}$ & $\begin{array}{l}\text { the slope of the isotropic normal compression } \\
\text { line in lnv - lnp' space }\end{array}$ \\
\hline$\kappa^{*}$ & the slope of the swelling line in lnv - lnp' space \\
\hline 1 & parameter controlling elastic stiffness \\
\hline$v$ & Poisson's ratio \\
\hline $\mathrm{M}_{\mathrm{u}}$ & constant in the Drucker-Prager modification $(\mu)$ \\
\hline$\beta^{\mathrm{G}}$ & $\begin{array}{l}\text { the overconsolidation parameter for stiffness in } \\
\text { BRICK model }\end{array}$ \\
\hline$\beta^{\varnothing}$ & $\begin{array}{l}\text { the overconsolidation parameters for strength } \\
\text { (failure angle) in BRICK model }\end{array}$ \\
\hline $\mathrm{L}_{(\mathrm{b})}$ & the array of string length in BRICK model \\
\hline OCR & over-consolidation ratio \\
\hline SBP & self-boring pressure \\
\hline B & the width of the excavation \\
\hline $\mathrm{L}$ & length of the excavation \\
\hline TBM & tunnel boring machine \\
\hline SCL & sprayed concrete lining \\
\hline $\mathrm{RB}$ & ring beam \\
\hline
\end{tabular}

\section{PREFERENCES}

Bologna, P. (2017) Benchmarking empirical methods of prediction of ground movement for deep excavation. MSc thesis, University of Cambridge.

Chen, Y. et al. (2015) Application of the observational method on Crossrail projects, in Crossrail Lessons Learnt Conference, London. UK. London.

Chen, Y. (2018) Application of new observational method on deep excavation retaining wall design in London Clay', $\mathrm{PhD}$ thesis in preparation, University of Cambridge.

Crossrail, (2009) Geotechnical Sectional Interpretative Report; Report 1\&2, 3, 4; internal references: 1D0101-G0G0000549,550 and 551.

Crossrail, (2017) rout map visited in November 2017, web link: http://www.crossrail.co.uk/route/maps/regional-map

Ellison, K. C. (2012) Constitutive Modelling of a Heavily Overconsolidated Clay. $\mathrm{PhD}$ thesis, University of Cambridge.

Farooq, I. et al. (2015) An innovative Verification Process speeds construction of Crossrail's Moorgate shaft, Geotechnics ICE.

Fuentes, R., Pillai, A. and Devriendt, M. (2010) Short term three dimensional back-analysis of the One New Change basement in London, pp. 1-6. Available at: http://discovery.ucl.ac.uk/1318407/

Hardy, S. et al. (2017) New observational method framework and application, Proceedings of the 19th International Conference on Soil Mechanics and Geotechnical Engineering, Seoul, Korea.

Gaba, A. R. et al. (2003) Embedded retaining walls: guidance for economic design, Proceedings of the ICE - Geotechnical Engineering. doi: 10.1680/geng.2003.156.1.13.

King, C. (1981) The stratigraphy of the London Clay and associated deposits. Tertiary Research Special Paper, No. 6. Rotterdam, Backhuys.
Mills, C. (2016) Project in focus -Crossrail Whitechapel Station, Proceedings of Basement and Underground Structures, October, London, UK.

Pantelidou, H. and Simpson, B. (2007) Geotechnical variation of London Clay across central London, Géotechnique, 57(1), pp. 101-112. doi: 10.1680/geot.2007.57.1.101.

Pillai K.A. (1996) Review of BRICK model of soil behavior. MSc dissertation, Imperical College, London.

Pillai, K.A. et al. (2011) Back-analysis of a basement with a raft foundation in overconsolidated stiff clay, Proceedings of 15th European Conference on Soil Mechanics and Geotechnical Engineering, Athens, Greece. Available at: http://discovery.ucl.ac.uk/1323408/

SCOUT. (2007) D18 Report on Observational Method under the Framework of Eurocodes. European Commission Sixth Framework Programme. Project no: 516290. Re- port ref no: SB.DTTAP-NOT-6.045. Arup Geotechnics.

Simpson, B. (1992) Retaining structures: displacement and design, Geotechnics, 4, pp. 541-576.

St. John, H.D., Potts, D.M., Jardine, R.J., and Higgins, K.G. (1992) Prediction and performance of ground response due to the construction of a deep basement at 60 Victoria Embankment. Proc., Instn, of Civ. Engrs., Part1, Vol.92, pp. 449-465.

Yeow, H. (2014) Application of observational method at Crossrail Tottenham Court Road station, Geotechnical Engineering, 167(GE2), pp. 182-193.

Yeow, H. and Feltham, I. (2008) Case histories back analyses for the application of the Observational Method under Eurocodes for the SCOUT project, in 6th international conference on case histories in Geotechnical Engineering, Arlington, VA, pp. 1-13.

Zdravkovic, L., Potts, D. M. and John, H. D. S. (2005) Modelling of a 3D excavation in finite element analysis, Géotechnique,55(7), pp. 497-513. doi: 10.1680/geot.2005.55.7.497. 